\title{
Micro-mechanical behaviour of artificially cemented sands under compression and shear
}

\author{
W. WANG*, V. NARDELLI† and M. R. COOP†
}

\begin{abstract}
The mechanical behaviour of cemented sands at macro-scale has been widely studied in the past, while there is still a lack of laboratory test data for the micro-mechanical response. Therefore, a series of uniaxial compression and tangential shear tests on artificially cemented sand particles have been conducted using a microscope to observe their behaviour. First, the consistency of cemented particles with different cementing agents is discussed. Three breakage modes are proposed according to the images taken using a microscope camera. A new parameter named 'local roundness at contact' is introduced to emphasise the effect of contact morphology on sample strength. Moreover, the effect of bond thickness on the mechanical response of cemented particles has been investigated. Finally, the shear strength parameters of artificially cemented sand samples have been determined for two different sample diameters.
\end{abstract}

KEYWORDS: laboratory tests; particle-scale behaviour; sands

ICE Publishing: all rights reserved

\author{
NOTATION \\ $c$ cohesion intercept \\ $D$ diameter of the bond \\ $R_{\text {ins }}$ radius of the maximum inscribed circle of the particle outline \\ $r_{\mathrm{c}}$ local radius of curvature at the contact region \\ $t$ thickness of the bond \\ $\phi$ coefficient of friction
}

\section{INTRODUCTION}

Mechanical characteristics of bonded sands at macro-scale have been previously studied by conducting laboratory tests, including triaxial and direct shear tests, on both naturally cemented sands and those artificially cemented using, for example Portland cement or gypsum (e.g. Lade \& Overton, 1989; Airey, 1993; Coop \& Atkinson, 1993; Cuccovillo \& Coop, 1999; Alvarado et al., 2012a, 2012b). Cook et al. $(2011,2015)$ have emphasised the effect of the microstructure of sandstones including pore size distribution, bond to grain ratio and contact length. According to Jiang et al. (2012a, 2012b), the mode of bond failure was determined by the bond thickness. Thin bonds are formed by a cementing agent filling around the contact between two particles that touch directly, while thick bonds bridge the space between two particles that would not otherwise touch.

Wang \& Leung (2008a, 2008b) formulated a discrete element method (DEM) model to simulate cementation, emphasising the role of bond breakage and the dilatancy on the cemented sand response. A simpler DEM modelling technique consists of using parallel bonds, but Cheung et al. (2013) have found it difficult to obtain an accurate simulation for the behaviour of cemented sandstones because of the large number of parameters required with no existing micro-scale

Manuscript received 10 November 2016; first decision 13 May 2017; accepted 12 May 2017.

Published online at www.geotechniqueletters.com on 29 June 2017.

${ }^{*}$ City University of Hong Kong, Hong Kong.

†University of Hong Kong, Hong Kong; formerly City University of Hong Kong.

tUniversity College London, London; formerly City University of Hong Kong. understanding of their likely values, so that they simply had to be calibrated by curve fitting of triaxial test data.

While there have been many attempts to model bonds, very few examined their micro-mechanics. This research therefore aimed to explore the behaviour of a pair of artificially cemented particles using a microscope camera to observe the failure modes. Their compression behaviour was investigated along with shear behaviour. Uniaxial compression tests were performed on particles bonded either with Portland cement or gypsum plaster, but for the shearing behaviour only grains bonded using Portland cement were studied. The compression test configuration is superficially similar to uniaxial compression strength (UCS) tests. However, both the particles and bonds might deform and crush during compression, each having a different strength and stiffness. Moreover, the geometry of the interface between the two might affect the behaviour. These conditions are therefore more complex than those of UCS tests in which a uniform cylindrical sample is subjected to a nominally uniform stress regime.

\section{APPARATUS AND MATERIALS TESTED}

Figure 1 shows the experimental equipment used for the compression tests, which consists of a loading machine and a microscope camera combined with a high-intensity lighting system for the camera. During the compression tests, the lower loading platen (1) moved up at $0 \cdot 1 \mathrm{~mm} / \mathrm{min}$ while the upper frame (2) was fixed, resulting in the cemented particles (3) being compressed uniaxially. Forces and displacements were measured by a load cell (4) with a capacity of $800 \mathrm{~N}$ and a linear variable differential transformer (LVDT) (5) with a precision of $\sim 0.2 \mu \mathrm{m}$, mounted below the load cell to eliminate compliance effects. The failure process of the cemented particles was captured by a microscope camera (6) of $50 \times$ magnification. Using high-intensity lights (7), highquality videos could be made.

The shear tests were carried out using a custom-made inter-particle loading apparatus (Senetakis et al., 2013) that has been upgraded to improve the number of testing modes, its stiffness and accuracy (Nardelli et al., 2016). The apparatus (Fig. 2) consists of a loading frame (a), a sled (b) and three loading arms, each equipped with a micro-linear 


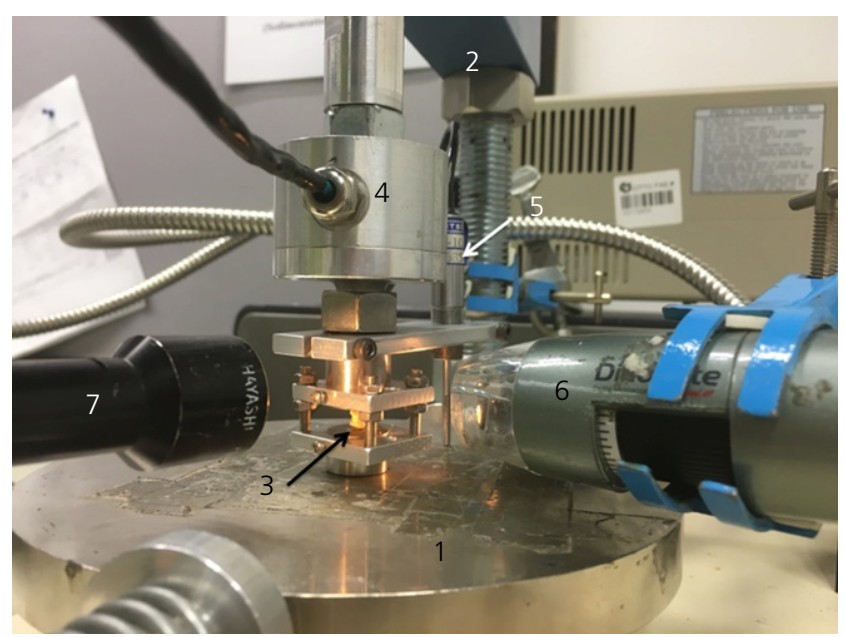

Fig. 1. Testing apparatus for uniaxial compression tests: (1) lower loading platen, (2) upper frame, (3) cemented particles, (4) load cell, (5) LVDT, (6) digital microscope camera, (7) highintensity fibre-optic lights

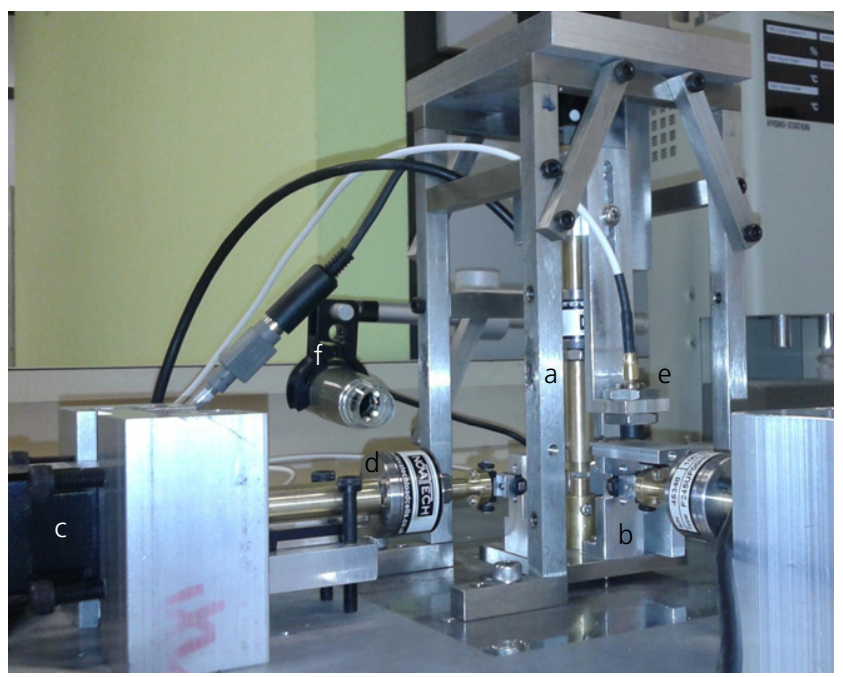

Fig. 2. Inter-particle loading apparatus for shear tests: (a) loading frame, (b) sled, (c) micro-linear actuator, (d) highresolution load cell, (e) eddy-current displacement sensor, (f) digital microscope

actuator (c) and a load cell (d, capacity: $100 \mathrm{~N}$ ). The displacements are measured using three non-contact eddycurrent sensors (e, resolution: $10^{-5} \mathrm{~mm}$ ). The two ends of a cemented pair of particles were glued to brass holders using epoxy resin and these were mounted onto the sled and the vertical arm of the apparatus. A shear test was carried out applying a constant vertical force to the sample and then shearing it at a constant displacement rate until breakage occurred. The tangential force was applied along a line that bisected the sample to minimise any bending moments. Two orthogonal digital micro-cameras (f) facilitated the test preparation and monitored the sample response.

Leighton Buzzard sand (LBS) was tested. The particles had dimensions ranging from 2.36 to $5.00 \mathrm{~mm}$ and were cleaned by ultrasound, removing oil and dust on the particle surfaces aiming to improve the bonding between the cement and sand. LBS is a quartz sand with few initial internal defects (Zhao et al., 2015). Portland cement and gypsum plaster were used as bonding agents to investigate the effect of different bonding materials on the cemented

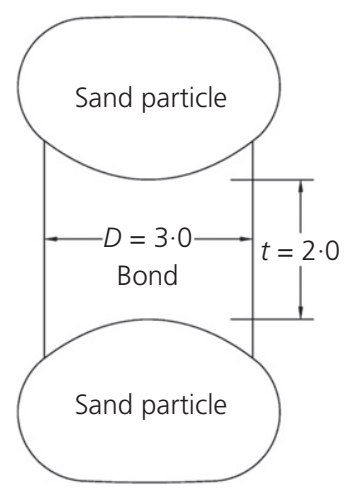

(a)

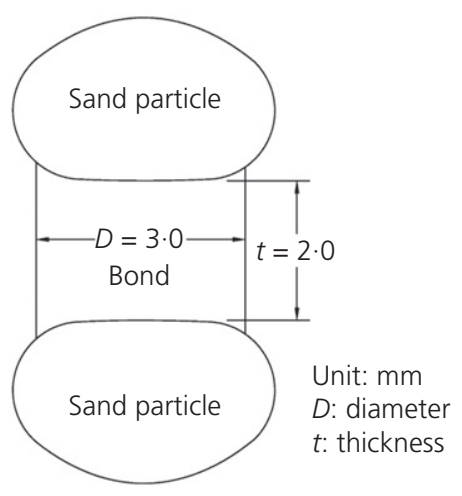

(b)
Fig. 3. Different cemented particle configurations: (a) LLR at contact, (b) HLR at contact

grain strength, making samples of cemented LBS particles using Portland cement as a cementing agent (PCLBS) and cemented LBS particles using gypsum plaster as a cementing agent (GPLBS), respectively. The water content for each cementing agent was the optimum to achieve maximum strength, which was around $40 \%$ for Portland cement and $25 \%$ for gypsum plaster. Two types of custom-made moulds were designed for the preparation of samples with a bond diameter of $3 \mathrm{~mm}$ and bond thicknesses nominally of 1 or $2 \mathrm{~mm}$. However, the irregularity of the natural shape of the particles, which is quantified later by their local roundness (LR), led to some variability in bond thickness; therefore, these thicknesses are approximately average values. PCLBS and GPLBS samples were cured for 7 and 2 days, respectively. For each sample, new sand particles were used, because they were often damaged during the tests.

It should be highlighted that there are differences between the simplistic geometry of the cemented particles used here and that of real bonded sands. The bonds were wide, having the same diameter as the particles and mostly they were thick. However, cement in natural weak quarzitic sandstones does not tend to be uniformly distributed, but generally tends to cluster at some, but not all, particle contacts, so that the bonds can be thick and wide (e.g. Alvarado et al., 2012 b), in a not dissimilar manner to those tested, although sometimes the large bonds would probably contact more than two particles. Making such tiny bonds was challenging and what has been achieved represents only a first, simple step.

For GPLBS, two groups of samples with different contact surface morphologies were prepared (Fig. 3). In one group, the flatter side of the LBS particles contacted with the gypsum bond (a), while in another group, the sharper side contacted the bond (b). The flatter side was identified as the side that the particles came to rest on when dropped onto a surface. The two groups of samples were tested to investigate the influence of contact morphology on strength.

\section{RESULTS}

The investigation of the consistency of mechanical response for each sample in compression was the first step to guarantee the reliability of tests. Both sets of data show considerable scatter and their causes are discussed below. For PCLBS, Fig. 4(a) shows less consistent results and a wider variation range in stiffness compared with GPLBS in Fig. 4(b). Besides, the stiffness of GPLBS is higher than that of PCLBS. Figure 4 shows data only for nominal bond thicknesses of $2 \mathrm{~mm}$, for which the mean value of peak force of PCLBS is $262 \mathrm{~N}$ with a standard deviation of $51 \mathrm{~N}$, while 


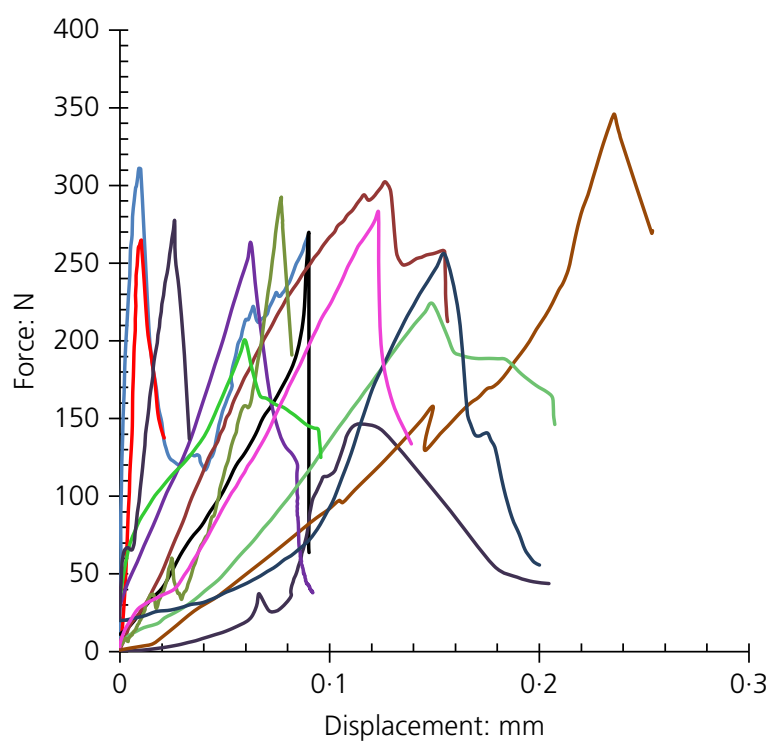

(a)

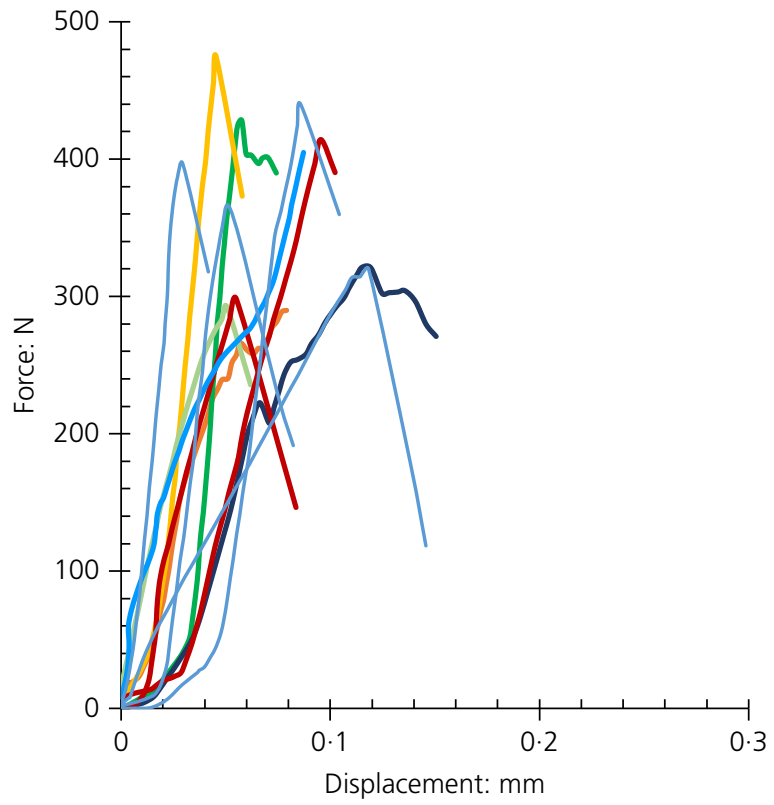

(b)

Fig. 4. Consistency of cemented LBS particles with a bond thickness of $2 \mathrm{~mm}$ tested in compression: (a) Portland cement, (b) gypsum plaster

that of GPLBS is $364 \mathrm{~N}$ with a standard deviation of $61 \mathrm{~N}$. A total of 50 samples of GPLBS with $2 \mathrm{~mm}$ bond thickness were tested, not all of which are shown in Fig. 4 for clarity, although this average is for the entire dataset. A further 26 GPLBS samples with bond thicknesses of $1 \mathrm{~mm}$ were tested. The study therefore focused on the GPLBS because gypsum plaster performed more consistently as a cementing agent, as is clear from Fig. 4.

\section{Breakage modes for GPLBS}

Three typical breakage modes for compression were identified for the GPLBS with bond thickness $t$ of $2 \mathrm{~mm}$. The images of different loading stages corresponding to the force-displacement curves (Fig. 5) for the three modes are illustrated in Figs 6-8. Creating a repeatable cement geometry was extremely difficult at this very small size, particularly since the particle sizes and geometries vary. Some

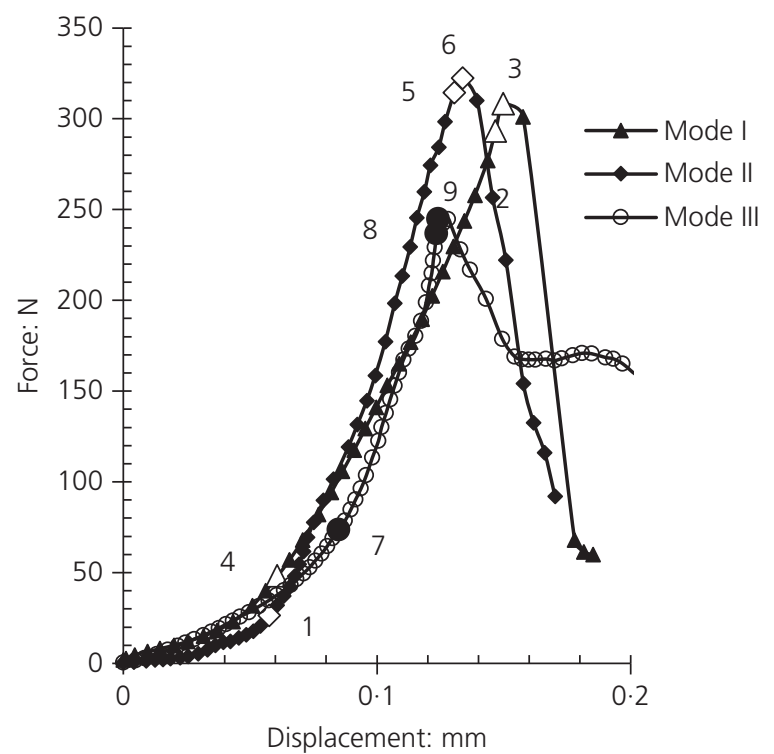

Fig. 5. Force-displacement curves for gypsum cemented particles for breakage modes I-III

small defects can therefore be seen in the cement geometry; however, these do not seem to have influenced the failure patterns and their removal would have been impossible without damaging the bonds.

For mode I, the lower particle crushed at point 2 in Figs 5 and 6 , corresponding to $\sim 0.8 \mathrm{~s}$ before the peak point 3 , as indicated by the brighter region inside the particle (Fig. 6 (2)). Since this bright region is a new and localised feature, it can only result from damage, and Wang \& Coop (2016) have shown that it often occurs immediately prior to failure in single-particle tests. Failure of some particles could be expected since Wang \& Coop (2016) had found that this size of single particle typically has peak forces in the range $100-300 \mathrm{~N}$, similar to these tests. It is noted that the particle broke with no immediate effects on the force-displacement response, at least for a small time and displacement interval until at the peak a fracture quickly propagated through the bond vertically, resulting in a sudden drop of force.

Figure 7 illustrates a typical example for breakage mode II. Once the lower particle broke in Fig. 7 (5), as indicated by the bright region, a crack occurred along a single inclined shear band, which involved the whole bond and contact interface. Here the breakage mode is defined by the fracture inclination of cement, regardless of whether the particle crushed prior to fracture initiation or not. Breakage mode III is a combination of modes I and II. Comparing images in Fig. 8 (7) and (8), a small crack, highlighted with a circle, initiated at the upper cement contact interface before the peak in the force-displacement curve. Then it propagated along both the loading axis and an inclined shear band at the same time. In this case, no particle breakage was observed.

Based on the Griffith (1924) criterion, many investigations have been made of the mechanisms of fracture (e.g. Janach, 1977; Batzle et al., 1980; Sammis \& Ashby, 1986). For mode I in this study, the bond failed possibly due to the radial tensile stress within the column, known as 'vertical slabbing'. Microcracks propagated and combined leading to contiguous vertical failure planes under tension. The growth of a crack inclined to the vertical loading axis as in mode II is more common for compression tests with modest confining pressures. Perhaps, the particles contacting the bond might provide some lateral confinement so that failure occurs in a shear band. In mode III, both the breakage mechanisms apply. It can be concluded that for all modes, while particle 


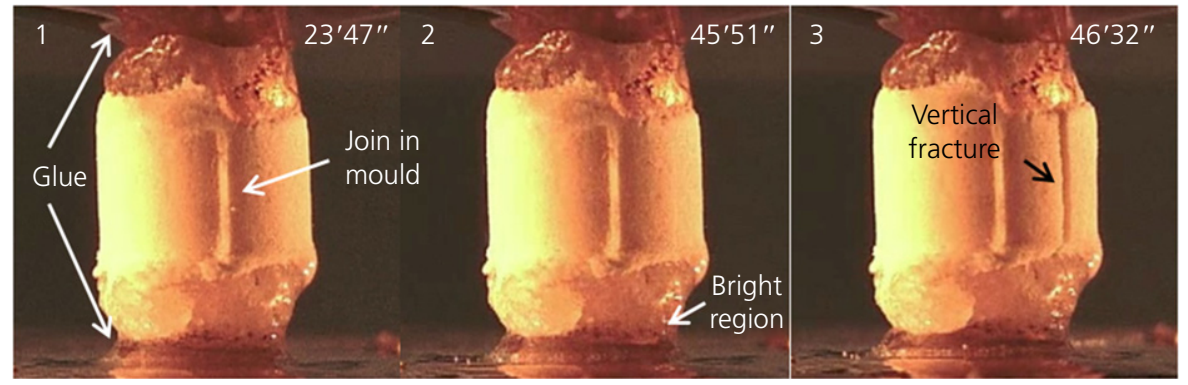

Fig. 6. Breakage mode I: crack in the bond occurs along the loading direction

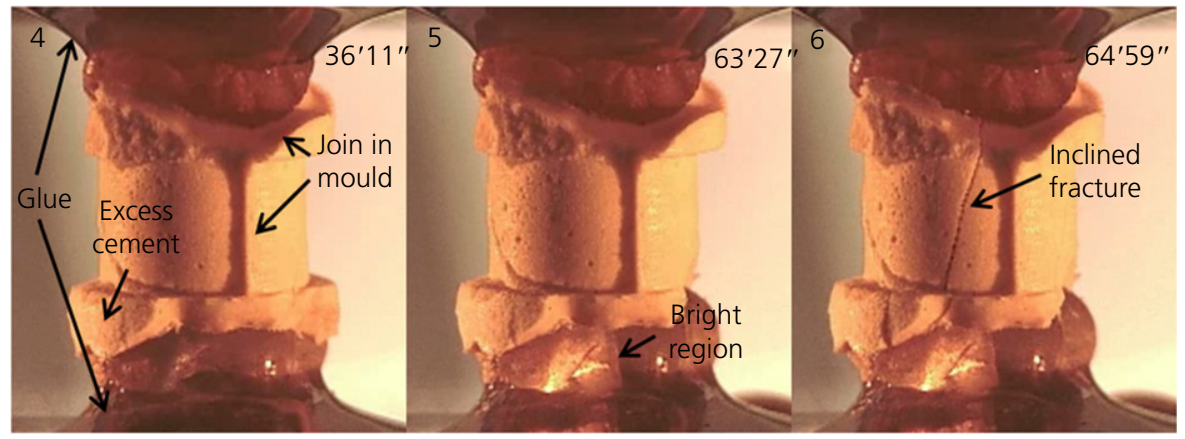

Fig. 7. Breakage mode II: crack in the bond occurs along a single inclined shear band which involved the whole bond

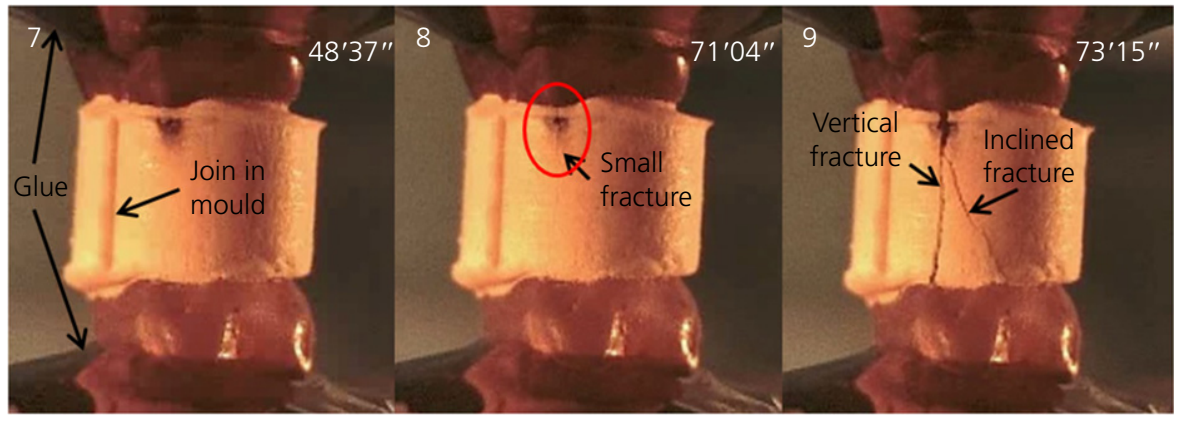

Fig. 8. Breakage mode III: crack in the bond occurs along loading direction and inclined shear band which involved the whole bond

breakage may occur first, the bond behaviour dominates the final failure and there is no clear effect of initial particle breakage on peak strength as all these three examples have similar strengths.

\section{The effect of contact morphology between the particle and bond on the strength}

The inconsistency of the peak force of the samples of the same particle size and bond dimension is perhaps related to the different contact morphologies between the particles and the bond. To investigate the influence of contacts on mechanical response, a shape descriptor named local roundness (LR) has been considered (Wang \& Coop, 2016). It describes the sharpness at the contact region of a particle, defined as

$$
\mathrm{LR}=\frac{r_{\mathrm{c}}}{R_{\text {ins }}}
$$

where $r_{\mathrm{c}}$ is the local radius of curvature at the contact region and $R_{\text {ins }}$ is the radius of the maximum inscribed circle of the particle outline. A higher LR indicates a flatter surface.

Here the average values of LR obtained along the contact profile from the two orthogonal images were calculated and the minimum value from the two directions was used,

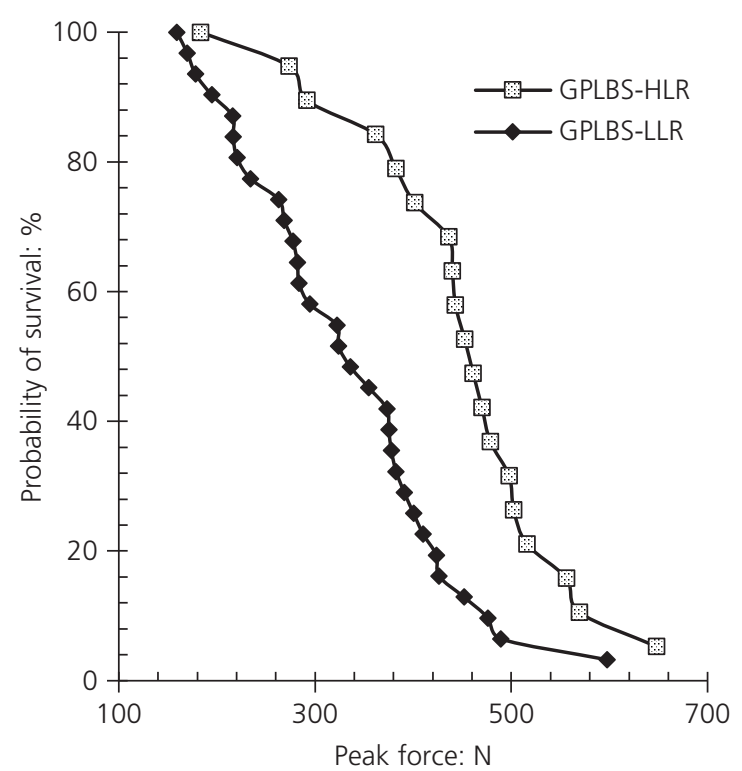

Fig. 9. The effect of particle LR at contact surface on the peak force of cemented particles 


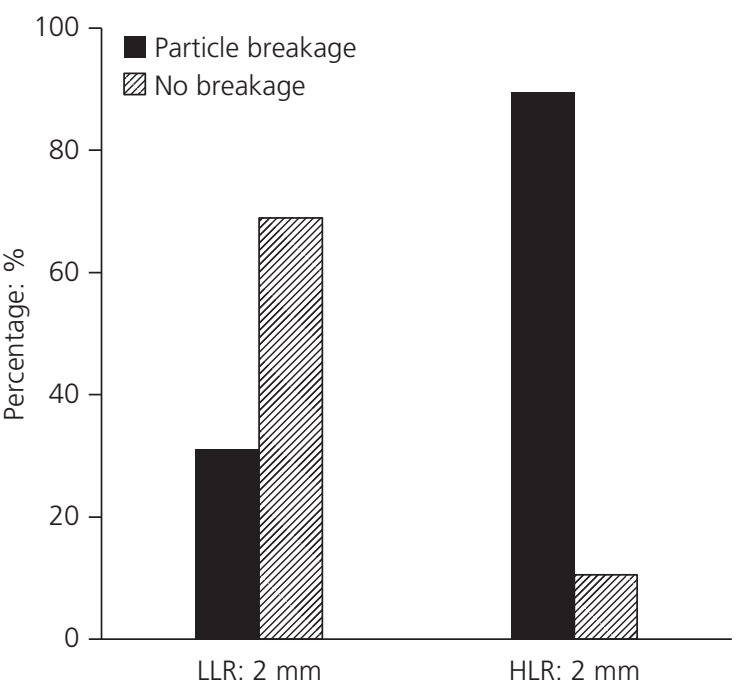

(a)

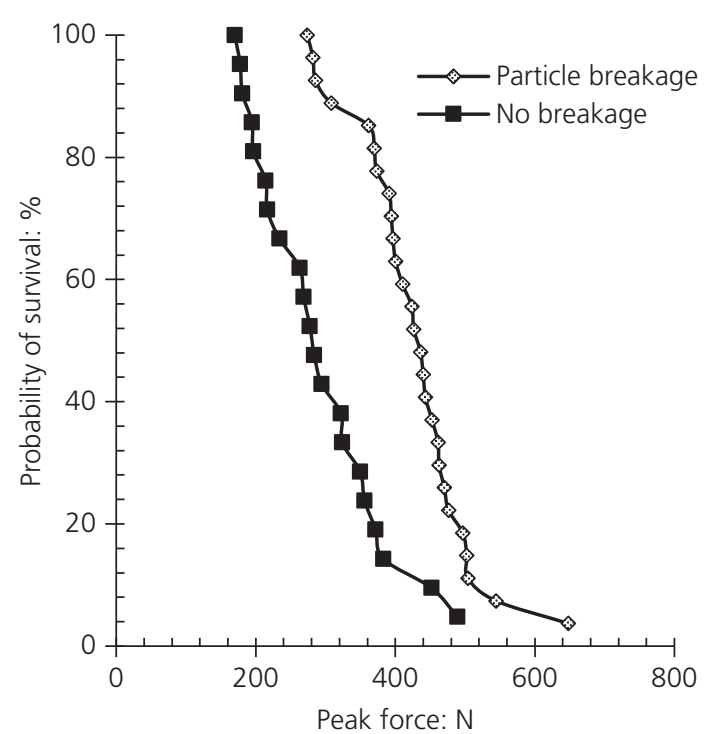

(b)

Fig. 10. (a) The LBS particle breakage ratio for cemented particles with different particle LR at the contact surface, (b) the effect of the peak force on particle breakage

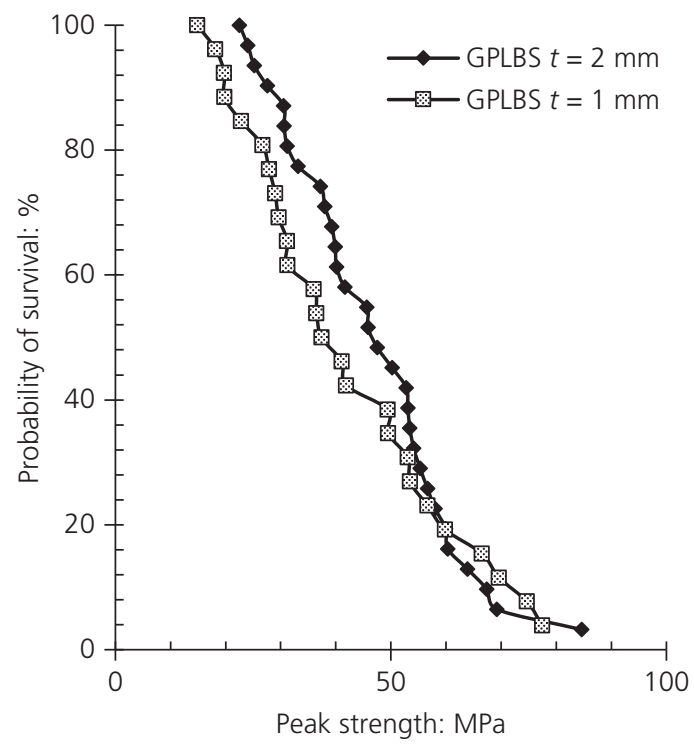

Fig. 11. The effect of bond thickness on the strength distribution of GPLBS particles

defined as 3D local roundness. As mentioned before, two groups of GPLBS samples were prepared obtaining high local roundness (HLR) samples cementing the flatter sides of the LBS particles (average $L R=1.92$ ) and low local roundness (LLR) samples by using the side opposite to the flatter one (average LR $=0.43$ ).

Weibull (1951) statistics were used to study the particle strength. Figure 9 shows the effect of LR at the interface on the peak force. An HLR gives strengths higher than LLR, with characteristic forces of $477 \mathrm{~N}$ for HLR and $376 \mathrm{~N}$ for LLR, respectively. Figure 10(a) illustrates the sand particle breakage ratio for the two groups. For flat contacts (HLR), the percentage of LBS breakage is much higher $(90 \%)$ than that for LLR $(31 \%)$. Therefore, the assemblies with higher strengths are also those where particle breakage occurs (Fig. 10(b)). For the LLR particles, the lower strength and lack of breakage may result from the stress concentration at the particle-cement interface causing an earlier failure, prior to the particles reaching their strength.

\section{Effect of bond thickness on sample strength}

Figure 11 shows the effect of bond thickness on the strength for the GPLBS. The stresses were calculated as the ratio between the vertical force and the initial horizontal area of the sample, since the radial deformation during the tests could not easily be determined because of their very small size and brittleness. The strengths of cemented particles with $2 \mathrm{~mm}$ bonds are slightly higher than those of $1 \mathrm{~mm}$, which probably arises from the complex interaction of the cement and particle failure.

Figure 12(a) shows the results in terms of stress-strain of five compression tests on PCLBS samples having diameter $D=4 \mathrm{~mm}$ and five tests for $D=3 \mathrm{~mm}$. For these earlier tests, the thickness of the bonds was not fixed and it was measured after the end of the tests using a digital calliper assuming that the bond size did not change significantly during the compression stage. The stress-strain curves are characterised by stiffnesses and peak values that are quite variable but not clearly affected by the diameter of the samples. Breakage of the cement bond was observed at the end of every test conducted, with no evidence of particle damage.

The relationship between the maximum normal stress and sample thickness for all the tests performed on PCLBS is illustrated in Fig. 12(b). The graph shows a slight increase in peak stress with cement thickness for both 3 and $4 \mathrm{~mm}$ dia. samples, with the possibility of strength bifurcation for high bond thicknesses $(>2 \mathrm{~mm})$, which may lead either to higher or lower sample strengths. The strengths measured for both the 3 and $4 \mathrm{~mm}$ dia. samples appear to be within the same range, but slightly higher peak stresses for those of $3 \mathrm{~mm}$ can be observed. This increase in peak strength with the increase in thickness seems in contradiction with the lower strength values measured from tests on various rock types, where the larger ratios between sample length and diameter correspond to lower sample strengths (Tuncay \& Hasancebi, 2009). The results are probably affected by the contact geometry at the interface between the sand grains and the cement bond and by the fact that these samples are not a homogeneous single material like rock samples but complex 


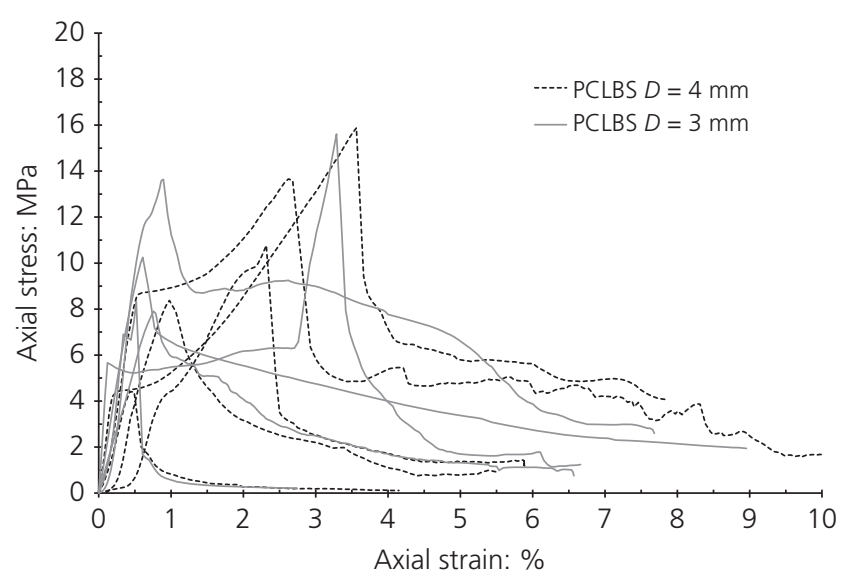

(a)

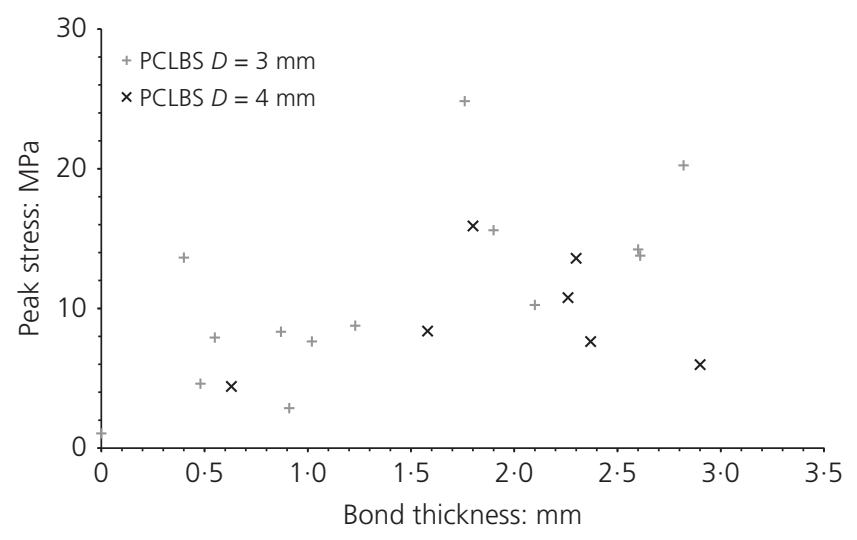

(b)

Fig. 12. (a) Compression test results for PCLBS samples and (b) effect of bond thickness on the peak strength of PCLBS

assemblies of bonded particles. The contrasting effect of thickness for the two bond types also indicates that the bonding material may also play a role.

\section{Shearing behaviour of PCLBS}

Figure 13 shows the results of four shear tests on PCLBS samples for 3 and $4 \mathrm{~mm}$ dia. samples confined at 1 and $2 \mathrm{~N}$. The force-displacement curves show a clear influence of the confining force on both stiffness and peak values, especially for the $4 \mathrm{~mm}$ samples. The failure envelopes for the two groups of samples are illustrated in Fig. 14. The scale of the horizontal axis in the graph is enlarged with respect to the vertical for clarity and within the scatter the data are fitted with linear envelopes. The tests were carried out under confining forces between 1 and $3 \mathrm{~N}$, which are far below the strengths measured in uniaxial compression; higher values would lead to tangential forces too high for the apparatus capacity. Very high friction coefficients and a cohesive intercept of sample strength in terms of force were determined, which both increase with the sample diameter $\left(\phi=53^{\circ}\right.$ and $66^{\circ}$ and $c=2$ and $11 \mathrm{~N}$ for 3 and $4 \mathrm{~mm}$ diameters, respectively). Therefore, bond diameter has a much clearer effect on tangential strength than on compressive strength. Moreover, although the scatter of the data leads to uncertain values of $c$ and $\phi$, the sample strength clearly increases with the increase of the normal load. This agrees with previous research on quartz sands bonded with Portland cement tested using the triaxial apparatus (e.g. Consoli et al., 2012), where an evident increase in strength with confining pressure was observed. Particle breakage during shearing was never observed, perhaps because of the low normal loads.

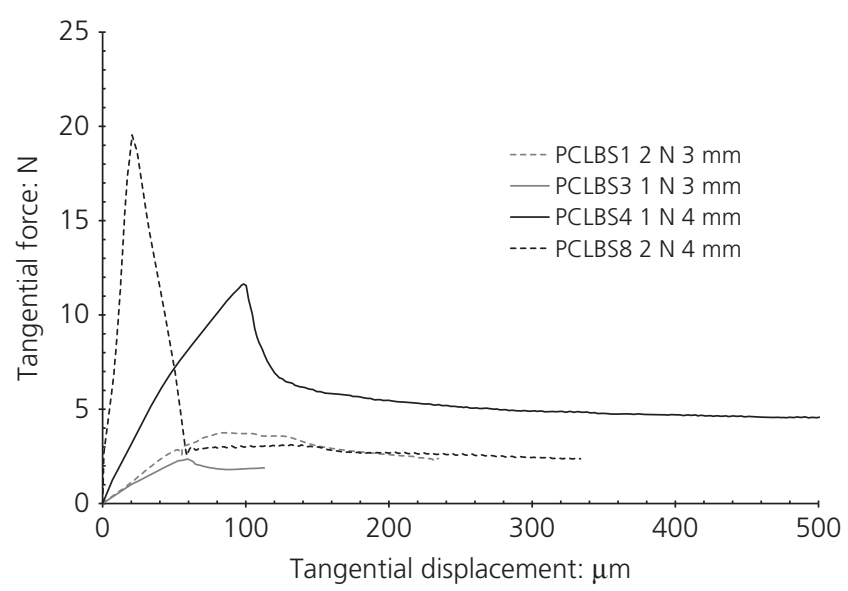

Fig. 13. Shear test results on PCLBS samples having different diameters ( 3 and $4 \mathrm{~mm}$ )

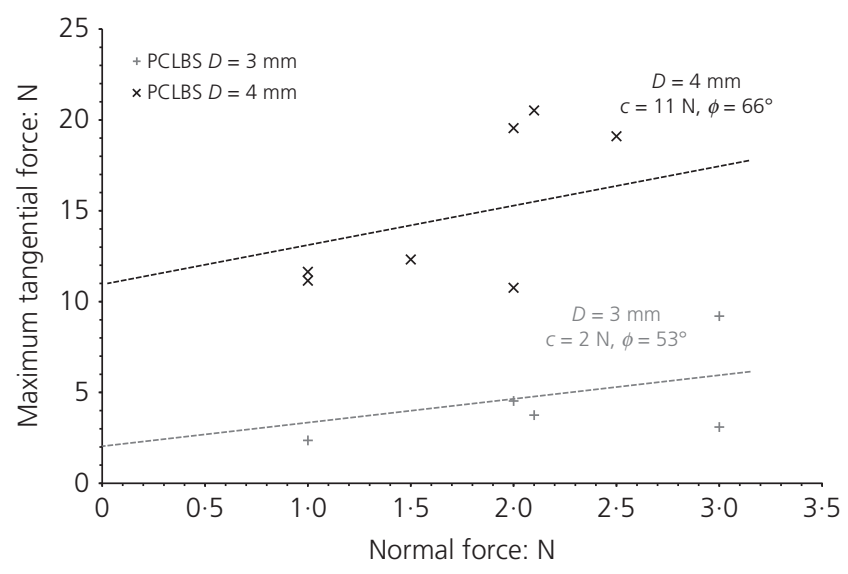

Fig. 14. Possible failure envelopes for PCLBS samples having different diameters ( 3 and $4 \mathrm{~mm}$ ) tested in shearing

\section{CONCLUSIONS}

A series of uniaxial compression and shear tests on cemented particles with different bond thicknesses, contact morphology and cement agents were performed to investigate the micro-mechanical behaviour of cemented particles. The data were quite variable, partly because of the difficulty of manufacturing such small cemented contacts. In compression, three breakage modes for the GPLBS were proposed: Mode I with cracks that initiate and propagate along the vertical loading axis, while for Mode II they propagate along a single inclined shear band. Mode III is a combination of these two modes. Failure of the bond, rather than that of the particle, is responsible for the peak strength of the assembly.

From research on the continuum behaviour of cemented sands in triaxial tests, it has often been assumed that cement breakage would precede particle damage in quartzitic materials because of the strong particles (e.g. Cuccovillo \& Coop, 1999). While no particle breakage was seen in shear here, significant particle breakage was seen in compression, although the cement bonds used were relatively large. The contact morphology plays an important role in the sample response and this contributes to the data scatter. Cemented particles with a flatter contact surface between sand and bond tend to be stronger so that there is more damage to the particles. The influence of bond diameter is much less clear in compression than in shearing, for which the strength and stiffness both increased significantly with diameter. 


\section{ACKNOWLEDGEMENTS}

The authors acknowledge Ms P.J. Jiang for performing some of the compression tests on PCLBS samples. This work was fully supported by a grant from the Research Grants Council of the Hong Kong Special Administrative Region, China (project no. CityU 112712) and Project T22-603/15 N (CityU 8779012).

\section{REFERENCES}

Airey, D. (1993). Triaxial testing of naturally cemented carbonate soil. J. Geotech. Engng. 119, No. 9, 1379-1398.

Alvarado, G., Coop, M. R. \& Willson, S. (2012a). On the role of bond breakage due to unloading in the behaviour of weak sandstones. Géotechnique 62, No. 4, 303-316, http://dx.doi. org/10.1680/geot.8.P.017.

Alvarado, G., Liu, N. \& Coop, M. R. (2012b). The effect of fabric on the behaviour of reservoir sandstones. Can. Geotech. J. 49, No. 9, 1036-1051.

Batzle, M. L., Simmons, G. \& Siegfried, R. W. (1980). Microcrack closure in rock under stress: direct observation. J. Geophys. Res. 85, No. B12, 7072-7090.

Cheung, L. Y. G., O’Sullivan, C. \& Coop, M. R. (2013). Discrete element method simulations of analogue reservoir sandstones. Int. J. Rock Mech. Mining Sci. 63, 93-103, http://dx.doi.org/10. 1016/j.ijrmms.2013.07.002.

Consoli, N. C., Cruz, R. C., Viana Da Fonseca, A. \& Coop, M. R. (2012). Influence of cement-voids ratio on stress-dilatancy behavior of artificially cemented sand. J. Geotech. Geoenviron. Engnng. 138, No. 1, 100-109.

Cook, J. E., Goodwin, L. B. \& Boutt, D. F. (2011). Systematic diagenetic changes in the grain-scale morphology and permeability of a quartz-cemented quartz arenite. AAPG Bull. $\mathbf{9 5}$ No. 6, 1067-1088.

Cook, J. E., Goodwin, L. B., Boutt, D. F. \& Tobin, H. J. (2015). The effect of systematic diagenetic changes on the mechanical behavior of a quartz-cemented sandstone. Geophysics 80, No. 2, 145-160.

Coop, M. R. \& Atkinson, J. H. (1993). The mechanics of cemented carbonate sands. Géotechnique 43, No. 1, 53-67, http://dx.doi. org/10.1680/geot.1993.43.1.53.

Cuccovillo, T. \& Coop, M. R. (1999). On the mechanics of structured sands. Géotechnique 49, No. 6, 741-760, http://dx.doi.org/10.1680/geot.1999.49.6.741.

Griffith, A. A. (1924). The theory of rupture. Proceedings of the first international congress for applied mechanics, Delft (Biezeno CB and Burgers JM (eds)). J. Waltman Jr, Delft, the Netherlands, pp. 55-63.

Janach, W. (1977). Failure of granite under compression. Int. J. Rock Mech. Mining Sci. Geomech. Abstr. 14, No. 4, 209-215.

Jiang, M. J., Sun, Y. G., Li, L. Q. \& Zhu, H. H. (2012a). Contact behavior of idealized granules bonded in two different interparticle distances: an experimental investigation. Mech. Mater. 55, 1-15, http://dx.doi.org/10.1016/j.mechmat.2012. 07.002 .

Jiang, M. J., Sun, Y. G. \& Xiao, Y. (2012b). An experimental investigation on the mechanical behavior between cemented granules. Geotech. Testing J. 35, No. 5, 678-690.

Lade, P. V. \& Overton, D. D. (1989). Cementation effects in frictional materials. J. Geotech. Engnng 115, No. 10, 1373-1387.

Nardelli, V., Coop, M. R., Vitone, C. \& Chen, S. (2016). The inter-scale behaviour of two natural scaly clays. Géotech. Lett. 6 , No. 3, 205-210, http://dx.doi.org/10.1680/jgele.16.00060.

Sammis, C. G. \& Ashby, M. F. (1986). The failure of brittle porous solids under compressive stress states. Acta Metall. 34, No. 3, 511-526.

Senetakis, K., Coop, M. R. \& Todisco, M. C. (2013). Tangential load-deflection behaviour at the contacts of soil particles. Géotech. Lett. 3, No. 2, 59-66, http://dx.doi.org/10.1680/geolett. 13.00019.

Tuncay, E. \& Hasancebi, N. (2009). The effect of length to diameter ratio of test specimens on the uniaxial compressive strength of rock. Bull. Engnng Geol. Environ. 68, 491-497, http://dx.doi.org/ 10.1007/s10064-009-0227-9.

Wang, W. \& Coop, M. R. (2016). An investigation of breakage behaviour of ingle sand particles using a high-speed microscope camera. Géotechnique 66, No. 12, 984-998. 247, http://dx.doi. org/10.1680/jgeot.15.P.247.

Wang, Y. H. \& Leung, S. C. (2008a). A particulate-scale investigation of cemented sand behaviour. Can. Geotech. J. 45, No. 1, 29-44.

Wang, Y. H. \& Leung, S. C. (2008b). Characterization of cemented sand by experimental and numerical investigations. J. Geotech. Geoenviron. Engnng 134, No. 7, 992-1004.

Weibull, W. (1951). A statistical distribution function of wide applicability. J. Appl. Mech. 18, 293-297.

Zhao, B., Wang, J., Coop, M. R., Viggiani, G. \& Jiang, M. (2015). An investigation of single sand particle fracture using X-ray micro-tomography. Géotechnique 65, No. 8, 625-641, http://dx.doi.org/10.1680/geot.4.P.157.

\section{HOW CAN YOU CONTRIBUTE?}

To discuss this paper, please submit up to 500 words to the editor at journals@ice.org.uk. Your contribution will be forwarded to the author(s) for a reply and, if considered appropriate by the editorial board, it will be published as a discussion in a future issue of the journal. 